\title{
VIHO \\ - Efficient IT Support in Home Care Services
}

\author{
Niklas Johansson and Bengt Sandblad \\ Department of Information Technology, \\ division of Human-Computer Interaction, \\ Uppsala University, Sweden \\ \{niklas.johansson, bengt.sandblad\}@it.uu.se
}

\begin{abstract}
The main research objective for the VIHO project (Efficient Computer Support in Care for the Elderly) was to investigate how a home care and help service organization can be developed in order to be better prepared for future challenges, and how new technical systems could support the development process. We have studied the home help personnel's need for support and investigated how the new organization could be formed in order to provide a healthy and sustainable work. Initial focus has been on the essential parts of the work and how the work could be improved in the future, and not on design of the technical support systems. Our basic point of view has been that correctly used, new technology can contribute, so that work and organisation develops in a positive way, patients are feeling secure and the personnel's work environment is improved. This means that the organisation better can fulfil expectations and requirements. The professions can be strengthened and the organisation will be able to meet future challenges. In this report we briefly describe the results and the methods used in the project.
\end{abstract}

\section{Introduction and Background}

When an IT- system is introduced in a work situation, this will result in a number of consequences. Both the organisation and the work practices will experience substantial changes. The work tasks will not be performed in the very same way as before the introduction, since IT-systems by its nature facilitates, supports or sometimes prevents certain ways of working.

To obtain positive effects of introducing new IT-systems at a work place, we find that it is necessary to also develop the organisation and the work procedures. The work that is to be supported must be developed and improved prior to introduction of new technology. We find it not enough to use modern IT-systems to support work in 
the way it is currently performed, instead it is more important to see the potential in how the new technology can contribute to a positive development of the work and the organisation as a whole. In other words, we do not want to "cement today's cow paths", i.e. focus to hard on how the work is performed today. Our goal is to use technology in order to obtain positive changes, making the work more efficient and the work environment better.

The organisations for care of the elderly are today struggling with a number of problems and challenges. Work load is increasing since more people are becoming even older and are in an increasing need of attention and care. Different care professionals with different responsibilities will work together in a new ways. The economical resources within the welfare service are limited and impose requirements of effectiveness. Care takers themselves, and their relatives, are demanding more participation, information and service of a high quality. Nevertheless, there must be qualified personnel, sincerely devoted to the work, that can and want to work within the care sector in the future. This results in requirements of a good and healthy work with proper possibilities for development, efficient tools and a good working environment.

This report describes how we, base on previous research, have developed present work systems within care for the elderly and home health care, and proposed a new, future, work practice supported by new types of IT-systems. The project is called VIHO, a Swedish acronym for "efficient IT support in care for the elderly". Within this project we have used, and further developed, the future seminar model (Vision seminar) presented by [1]. Result from this work is manifold; the Vision seminar method has been improved, new work organisation and processes have been proposed to the home health care services and a preliminary design of a mobile IT system has been suggested.

\section{Research Framework}

Our approach is based on a number of basic values and fundamental conceptions that throughout have influenced our work. The essence of our relation to design of supporting IT-systems can be found early in the development process. First we design the work practice, then the support systems. Main concepts in our scientific approach are largely inspired by action research and a user centred method of working with description, analysis and design of IT-systems.

\subsection{Work Environment Aspects and IT Supported Work}

The way IT-systems are designed, and how they are used in practice, has a large influence on the working environment and the users' health. Issues of work environment have several dimensions and can be divided in three different parts:

Physical work environment concerns the ergonomy of the work environment. The work place must be designed to facilitate a healthy work. IT-supported work imposes requirements on the equipment. The monitor, keyboard, mouse, chair, table, lighting etc. shall all be ergonomically designed and adopted to the specific user and 
his or hers work situation. A poor physical work environment leads among other things to eye problems, strain injuries e.g. pain in neck, shoulders, arms and hands. There exists much knowledge about such problems [2].

Psychosocial work environment is the corresponding mental apprehension. It concerns how the personnel feel at work and how they experiences their work situation, including internal relations, relations with the management, provided and experienced social support etc. Bad such conditions do mostly result in a feeling of lack of support, stress and feeling ill at ease. IT support can affect such factors in a negative way if they are not carefully introduced. Examples of negative effects from IT are bad designed functionality for monitoring, time measurement and distribution of workload.

Cognitive work environment concerns the match between the IT-system and our and our cognitive skills. An example is when something in the work situation prevents us from using our knowledge and skills in an effective way in order to perform a task. A computer application can for example hinder from effective work, making the work problematic, difficult and hard to understand. It takes long time to perform, errors are frequent and the technology is confusing. It is important to understand these problems as they can affect the work negatively by making the personnel ineffective, insecure with feelings of irritation and stress as a consequence. Other important problems that can arise when using supporting IT systems in work are:

- Restrains and lack of freedom. The user becomes deskbound at the computer large parts of the day, mostly in static, monotonous positions.

- Controlled, a feeling of being governed in the work by the IT system, i.e. a lack of possibilities to control the system.

- Stress and the feeling of high demands from the work in terms of work load, time pressure and badly functional IT support are exceeding the resources at hand and the personal abilities.

- Stress related psychosomatic conditions, i.e. headache, annoyances, stomachache, lack of sleep.

- Physical problems, foremost ache in the back of the head, shoulders, arms and hands for example "mouse elbow".

It is important to recognise the strong interaction and relationship between IT systems, efficiency in the work process and the work environment. The supporting IT system must support efficiency in the work process and a healthy work environment. For a user, the largest work environment problem can be the feeling that you do not work efficient enough. Users are often much more concerned about the efficiency that e.g. about the physical work environment. Usability is in other words not only a question about work environment, but concerns very basic requirements for an efficient and sustainable work.

\subsubsection{Healthy Work}

An illustrative model describing healthy work was developed by Karasek and Theorell [3]. It describes the work situation in relation to the subjective experiences of demand, control and social support at work. Demands are the requirements laid 
upon the worker, what he or she is obliged to do. Control is the means the worker has to survey and handle the work situation. Social support refers to overall levels of helpful social interaction available on the job from co-workers, supervisors and other recourses. The primary work related risk factor is the workers' lack of control over how to deal with the job's demands and how to use their skills [3].

High demands are in other words not a problem, if they are combined with a high control and strong social support. But if the demands become too high in relation to control and social support, this will lead to high stress and an increased risk for bad health. The most favorable situation is one characterised by reasonable to high demands, high decision latitude and a strong social support [2].

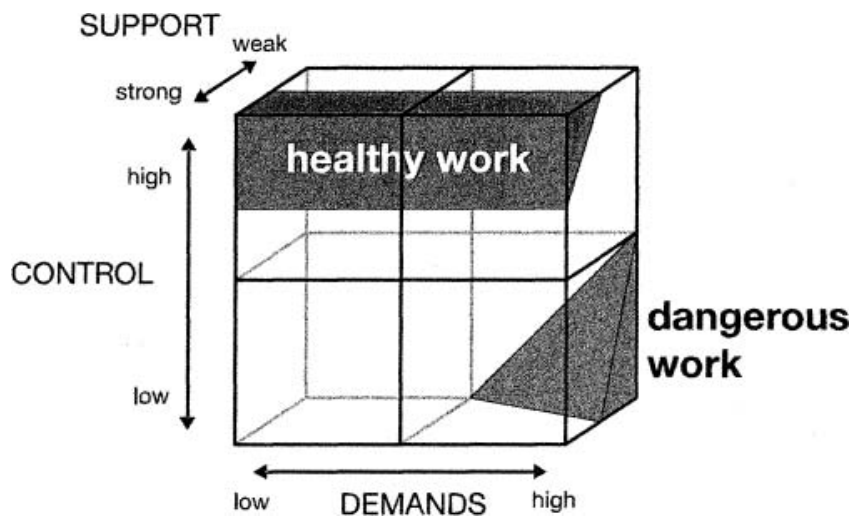

Fig. 1. Karasek and Theorell's model describing healthy work

Our experiences show that an increased computerization at a work place often results in experienced higher requirements [2]. This is by itself not a critical phenomenon, but it must be counterbalanced with increased control and social support. Today our experiences are the contrary; experienced control together with social support is often reduced together with an increased responsibility. This will lead to major problem in the work environment as well as increased risks for bad health and illnesses. When new work processes are designed, or when new technology is introduced, we must strive for increased control and social support.

\subsubsection{Insufficient IT Systems}

Today we can se several examples where new IT systems are introduced in work places, and how these systems unfortunately do not work properly in practice [4]. If it is possible to perform a work task in a more simple way than the one proposed by the IT system, the user will choose this simpler solution. Some reasons for an IT system to be neglected and not used as intended are:

- Bad adaptation of the system to local conditions at the work place 
- The system only provides support to some parts of the work processes

- Integration of a specific IT system with other involved systems is poor

- The system is difficult to use and it is characterised by bad usability

- The system does not give a proper feedback, not providing the user with an understanding of the system's benefits.

- The system does not support, but rather prevent, development of the work organisation

- Poorly technical performance makes the system slow and difficult to handle.

It is our belief that the required increase in control and support can be facilitated by a well designed and supporting IT system. Routines for support and control must also be well established in the organisation. Well designed and introduced IT systems can provide the user with efficient support like for example:

- Effective access to updated information

- Safe and secure storage and access of information

- Overview of the work situation and complex information sets

- Useful and efficient communication

- Control over the work situation through usable interfaces

- Control over the work situation through efficient planning tools

- Possibilities to evaluate the work process through access to historic information and evaluation tools

- Individual and collective development of competencies and work organisation

\subsection{Action Research Approach}

Our research is practical, performed in working life and can be considered as action research [5]. In the project described in this report, we have initiated a process in order to answer our research questions about how work processes and IT-systems can be jointly developed in practice. The objective is not to develop a new ITsupport system for the existing work organisation and work processes. The objective is rather to use the potential of new mobile technology to enhance the development of the work and its organisation as such. In this way we can fulfil two different goals. First we can make sure that the new IT-support system is well adapted to the new work processes. Secondly, we can use the potential of the new technology to support a good development of the work, and not to preserve old structures and processes.

A limitation with the action research approach is that the method can not be strictly evaluated. The conclusions can only be made whether the tested processes were (eventually) successful during the present conditions or not.

In comparison with an ethnomethodological approach, action research also aims at studying the subject in a connection with the organisation and its personnel. Action research aims at making a change, while ethnomethodology focuses on understanding. However, in order to propose a successful change, we find it important to first achieve understanding.

In our research we strive for an improved way to develop and introduce new supporting IT-systems at work places, and how to gain valuable knowledge about 
how this can be done in practice. To achieve this, we find that action research is a suitable approach.

\subsubsection{New Work Procedures}

As discussed briefly in the introduction chapter, an introduction of a new IT system in an organisation will undoubtedly change and affect the organisation and the way work is performed. The work will not be the same as before, but a new work has been formed. This change must be carefully handled.

A work is never perfect and performed in the very best and effective way. There is always room for improvements. When a supporting IT system is developed, that means that the IT system will be supporting a work that most likely has the potential to be changed to something better. Ineffective procedures can easily be made permanent. We find it better to develop IT systems that supports an improved way of working. In this way we can use technology as a driving force for work and organisational improvements.

We want to take control over the change of work that occurs when introducing a new IT system, and turn that change into something productive. Our approach is to first create a specification of a good way of working and thereafter design an IT system supporting that work. In this way we achieve two things; a new improved way of working and an efficient supporting IT system.

\subsubsection{Participative Design of IT Systems Supporting Work Processes}

Another main foundation in our work is that the ones that truly know best how to improve the way of working and what kind of support an efficient IT system can provide, is the personnel from the organisation, i.e. the ones that are to use the IT system as a tool in their future work. In line with a user centred system development approach [6], development of good, healthy and efficient IT systems are to be performed in close cooperation with the future users of the system.

A related research approach is participatory design [7]. There is a lot of research done concerning participatory design and user centred methods in general, and we will here just briefly conclude the most important.

User centred development is based on the principle that all development of technical IT systems for a workplace must be performed through active participation by persons that know the organisation and the work practice, i.e. the ones that actually performs the work. Experts from the outside can never fully understand the activities and can never alone decide whether a solution is good or bad. The ones that truly know the workplace and its practice can on the other hand not by them self describe and analyse their own organisation and work practice. Neither do they have the full competence to propose new, innovative solutions regarding the organisations as well as its IT support. It is only together and based on a suitable model for cooperation between future users and designers (researchers) that the work can succeed.

\subsubsection{To Use the Users' Knowledge}

Representatives of the organisation, the presumptive users, are experts in the way the work is performed today. They are the only ones that truly know the organisation in detail, details that are of grate importance when learning how systems and interfaces 
are to be designed. The way a work is actually performed in practice is not possible to completely describe, but has to be studied in practice. The work practice and the tacit knowledge that experienced professionals possess is very valuable and must influence the design [8].

Representatives also often possess valuable ideas of improvements, based on their experiences. However, it is our belief that these proposals should not be directly implemented, but have to be evaluated, expanded and arranged to fit in the new proposed way to work. New technical systems with its potential of information and communication facilitate totally new solutions. These possibilities must be worked out during the project.

As a part of the fundamental design of work, users' ideas and solutions to problems must be considered. But the designers are the experts of the final design solutions. On the other hand, no design solutions should be accepted without evaluation together with the users.

\subsection{The Iterative, User Centred Approach}

User centred system design does not imply that users themselves create the design of the IT system and its interface, but it aims at creating a creative environment and structure where designers and users can meet. In the VIHO project, our approach has been to create a basis to build further design work on. The basic main ideas behind the user centred model for system development are:

- Development work is conducted in collaboration between different competences, primarily between system developers and organisation representatives (users). They each have their own competences and area of responsibility but are parts of the same development work. The users are not service people or study objects, but is considered the part in the development project that possess the knowledge of how the concerned work actually is performed in practice. Participating users must be given required knowledge and the ones responsible for the design work must have good knowledge in human computer interaction and interface design.

- Development work is conducted in an iterative way where the phases analyse, design, construction and evaluation are repeated until the system has developed into a final version and the result is accepted by the involved parts. Representatives from the organisation must be different persons than the ones that are a part of the development work in order to minimize the risk of a misleading evaluation.

- Work is focused on prototypes of the planned system. A prototype changes during the project, from rough sketches on paper to an executable system. In this way it is important to use effective techniques for prototyping and evaluation.

- After implementation and deployment, the system must regularly be followed up and when necessary modified and complemented. 


\section{The VIHO project}

Our overall goal in the VIHO-project has been to develop future supporting IT system. To do this as good as possible, we have first defined and developed the work itself. In this way we will jointly develop both the work and the IT system.

The town-district "Kortedala" is located in the north-east part of Gothenburg in Sweden. Together with personnel from Kortedala home health care sector, we have developed a vision for the future work within the health care area and how this work can be supported by new IT systems. This vision can provide a basis for development of the new work organisation in detail, to describe new work processes and to implement new efficient and usable IT systems.

\subsection{Vision Seminars with a Work Group}

Practical work of envisioning the future work at the workplace was made in what we call Vision seminars [1] together with a work group from Kortedala home health care organisation. Vision seminars are performed in order to envision future possibilities of changes of a work organization as well as practices and are performed as group discussions about present practices, problems, goals, and possibilities. The inherent goal is a more efficient, stimulating and sustainable work. Objectives of the process in the VIHO project were to provide a foundation for a sustainable organisation of work, redesign of jobs, and to propose functionality for a future supporting IT system that enhances the workers" skills. To make "the future" concrete and a bit more tangible, we have worked with a perspective of five years, which in the beginning of the seminar series makes year 2008 .

The vision seminar series in the VIHO project was conducted during half a year with a working group of six assistant nurses, all experienced professionals from the elder care sector. Under the direction of four researchers, the group carried through twelve seminar occasions with two to three weeks between each occasion. During the seminars, the researchers role was to lead the discussions, provide input and to document and reflected upon the accomplish work. The reflections from one seminar served as an input for the next seminar.

At first, today's work was described in detail, closely followed by analysis of the needs for changes and development. Subsequently, important aspects of how the desirable future work would be carried out were formulated. These aspects included requirements of a changed work organisation, improved work processes and requirements of effective, supporting IT systems. Main objectives are to create a healthy and efficient work, at the same time as security and quality in health care are improved. 


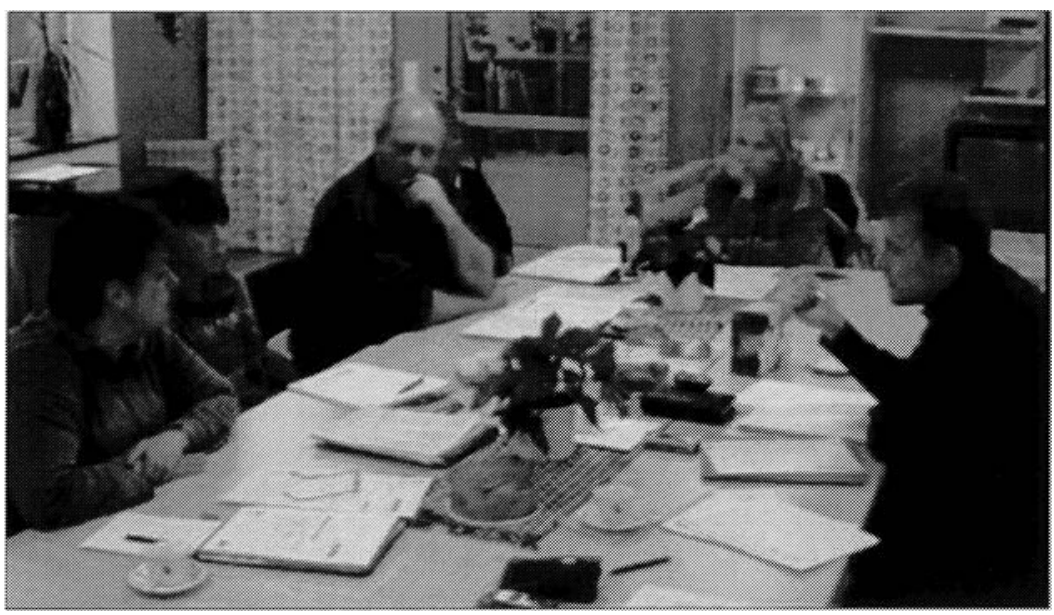

Fig. 2. Seminar with the work group

A fundamental approach has been to allow the process to take time. Meetings in the vision seminar series were held within two or three weeks of each other. This gave the participants time to reflect upon the previous meeting - consciously as well as unconsciously - and to prepare for the next meeting.

To facilitate the discussions and to prepare the participants for the next meeting, an assignment was often given for the next meeting. The participants were encouraged to engage their colleagues from their respectively workplace when completing the assignments. The distributed assignments were often related to how things are carried out, how and why, and they were closely coupled to the theme of the next seminar occasion. Here follows a number of brief examples of assignments:

- Write the essay "A day at work". Describe an average day filled with the activities that use to occur. Reflect upon what is $\mathrm{good} / \mathrm{bad}$, easy/hard, simpel/complicated, fun/boring etc. in the work.

- If your work place was your own company, and you were the manager, what would you do? How would you like your company to be organised and managed?

- What kind of communication are you carrying out daily? Why? Would you like some communication to be more extensive or more narrow than today? Why?

Every meeting had a theme, e.g. "Organization", "Technology" and "Information and communication". The working group discussed their work from different perspectives, the organisation, communication, skills, and collaboration and so on. Inspiration in the form of new knowledge on interesting topics e.g. organisation, ethics, and new technology were provided by internal or external lecturers. This put the participants in a better position to perform critical evaluations, creative thinking and to identify and propose solutions to problems at their own workplace. A number of seminar themes are here briefly presented. 


\subsubsection{Present Work}

The aim of this analysis was to document present work, tasks, cooperation, and workers' skills, and it extended through a number of working group meetings. Present conditions were investigated initially. Skilled people easily describe the work they are involved in at present, what works well, and what does not. Rather than making a list of a number of tasks that workers perform, a more detailed description such as a told narrative can capture the essentials of work in its context. In order to get an overview of the present work situation, the seminar group discussed questions as for example:

- What do you consider most important in your work?

- What do you appreciate most in your work?

- What work do you carry out really well?

- What does good quality mean in your work?

- Which technical systems do you use? For what purpose?

- Which information do you use in your work? For what purpose? Where? When? How?

- With which people do you communicate? What matters do you discuss? How? Why?

When collaboration is considered, the complexity of the work routines at a workplace becomes evident. Such aspects easily remain concealed if work is regarded as a set of individual tasks that have to be managed.

\subsubsection{Change of Work Procedures}

To stimulate proposal to a better, desirable work, the participants in the seminar series were to play with the thought "If my workplace was my own company and I were the boss, what would I do"? The assignment was approached in a number of ways, for example concerning:

- Economy

- Competence, education and training

- Use of working time

- Scheduling

- Work planning

- Work evaluation

- Communication

- Information

- Leadership

- Rewards

In this way we achieved a good understanding of how the work was presently carried out in the different work places. Furthermore, a number of issues to change and improve were recognised and documented. It is our experience that discussions like these mostly provides good ideas. When asking a question like "What does really hinder this?", it used to turn out that there are very few restrictions for changes in 
practice, and that much is not very difficult to accomplish. Some things are even possible to change instantaneously.

A question raised during this seminar was about awareness of costs for medical supplies. After discussion of the issue, an assistant nurse from the home health care decided to label all the medical supplies in the storeroom at her work place with the cost for each item. This appeared to make the personnel aware of the cost and less predisposed to waste the expensive material unnecessarily.

\subsubsection{Information and Communication Analyses}

To carefully examine what kind of information is handled during the work procedures, we asked the working group participants to collect forms, lists and other documentations means from their work. Use of information were analysed by means of what information is used and what is shared. Communication then is much relative and was more extensively documented in terms of who communicates with whom, why, where, when and how.

In this work the gathered materials from the participants were very useful. When working with the material, it became clear that the participants in the seminar group quite often used different name for the same kind of form. They also used the same form in different ways - and this in the very same local organisation.

\subsubsection{Scenarios}

At the end of the vision seminar the group described the future work in form of a set of scenarios. A scenario is a written description, or story, describing - in this case how the future work can be carried out. We wrote the scenarios iteratively together with the participants from the work group. The writing itself is valuable as it is a creative process where unformed thoughts have to be formulated in text.

Important parts of the scenarios were specified and described in terms of activity specifications. This is a more formally description of tasks that are performed, which information is used and produced, how persons communicate etc. Based on these scenarios and the activity specifications, we summarised the information and communication needs of the future work procedures.

Based on the written scenarios, simple and preliminary sketches of new supporting IT systems were carried out. In this way, the roughly designed IT-support systems are based on rather detailed descriptions of the proposed future work settings.

\subsubsection{Complimentary Work}

\subsubsection{Interviews}

The vision seminar process puts a grate focus on the participants in the seminar group. In order to not totally exclude other concerned professions, we conducted a number of interviews with key persons in the organisation. This was done in the latter part of the seminar series, based on the proposed new work taking shape. Results from the interviews where if necessary discussed during the seminars and included in the documentation.

These "external interviews" had two major purposes. At first we wanted to map other persons experiences. By exclusive concentrating on the people in the seminar 
group, other concerned professions were not allowed to be heard and we would risk getting a distorted notion of the work and the organisation.

\subsubsection{Field Studies}

To fully understand how a work actually is conducted, discussions in a seminar series are not sufficient. Field studies including observation of workers are an important prerequisite to design of support systems. Without field studies uninformed systems designers may draw attention to unimportant issues, draw false conclusions, and lead the work in an inappropriate direction. Knowledge must be obtained from the very place where the IT-system is to be implemented and used.

In parallel with the seminar series, two different workplaces represented in the seminar group were studied in more detail. Two one-day field studies were conducted to study the work in practice and to find additional important details in the work practice. Participatory observations were mixed with short interviews during the day.

\subsubsection{Vision Seminar Results}

Eventually, the work in the vision seminar resulted in a number of suggestions for improvement in order to achieve a good and healthy future work. We worked with the result in terms of aspects on the future work. These aspects are very specific for the work within the elder care in Kortedala, and some of them quite specific for the respective work place for each participant in the seminar group. Here follows a selection of the more general and concrete aspects on the proposed, future work.

\subsubsection{Autonomous Groups}

The groups carrying out the practical health care work should be autonomous and be given a broader, local, responsibility than today. They are to organise and carry out their own planning, dispose their own resources and undertake their own quality assurance. As discussed earlier, it is important that increased responsibility also is supported by increased possibilities.

It is our conclusion that it is locally, on the operative level where the work is actually performed, the best and most effective planning can be accomplish. It is also there the best priorities can be made. It is the working teams that possess the valuable knowledge of the actual conditions. It is down there, "on the floor", on site in the care takers home, where quality improvements can be achieved.

\subsubsection{Coherent Health Care Planning}

We want to achieve a common use within the organisation of the individual care plans used in the elder health care. The whole chain of care planning; from the very first decision of assistance, care planning, intervention planning, execution and documentation and finally follow-up and evaluation - all shall be well planed, well known and concurrent throughout the whole organisation These objectives already exist today, but they are poorly fulfilled. It is desirable that the health care personnel participate in the decisions of assistance to assure that the decisions become practical. 


\subsubsection{Increased Economic Responsibility}

The economical responsibility shall be moved further down in the organisation, down to where the costs appear. Providing the right means in terms of access to information, education, authority and competence, it is where the cost actually occurs that they can be controlled. To facilitate a more effective use of the resources, it shall be possible to make economic plans in advance, not just to be able to look backwards to se previous expenses.

\subsubsection{Increased Professionalism}

Occupations in the elder health care deserve a better reputation. The feeling of being branded as a maid is frequently encountered. We want to work for a more pronounced professionalism where the personnel really are allowed to perform the undertakings they are educated for. This is also facilitated by the earlier discussed aspects of autonomous groups and increased economic responsibility.

\subsubsection{A Healthy Work}

By a strong focus on the work environment, a number of aspects can be improved and a healthy work obtained. A well established staff welfare and influence on the organisation will decrease the sick leave and reduce the employee turnover. Consequently, this will attract new personnel and provide for a higher quality in the entire health care sector.

\subsubsection{Supporting the Future Work with IT}

Supporting IT systems can not by themselves fulfill an organisation's goals, but they can hopefully contribute by being a powerful support, and result in a positive development of work and services. The technology can be used as a driving force in development of the work. What we have found is that through the used participatory process, we have been able to develop new efficient work processes that not can be achieved without the new supportive technology.

To implement the new work procedures, effective information access and communication means is a necessity. A supporting IT system can, properly designed, meet these requirements and facilitate the future, proposed work. Here follows a selection of how technology can facilitate the requested changes of today's work described in terms of aspects in the previous chapter.

The proposed autonomous groups, carrying out the actual outside service, are to be given access to the information needed, on the very place where the work is conducted. This requires a mobile IT system providing access to e.g. schedules for both personnel and care takers, where planned and accomplished efforts are accessible. Further, medical information like patients medicine lists and general medical information are to be part of the accessible information.

The chain of care planning, essential for the coherent health care planning, shall be supported by an IT system accessible by all parts in the care chain. A well designed IT support provides easy information access.

Proper information access also provides for the proposed increased economic responsibility. Responsibility must be followed by authorization. A supporting IT system can provide necessary economic information, e.g. costs for services, materials and time as well as available resources and possibilities. Through that, 
home health care teams can be given larger economic responsibility followed by better possibilities to provide better care services. The most efficient economic control occurs when it is transformed into a real-time planning of the available resources. To achieve this, the economic planning, control and evaluation must be made where the costs occur, i.e. out in the operational teams.

\subsection{Design of Future IT Support}

The results above indicate where in the organisation and in the work practice improvements can be made, and where and how a supporting IT system can have a positive effect. The detailed functionality and design is not specified within the project. However, a knowledge base is established and first prototype for the design has been developed.

It is important to fully understand that a professional user's task or goal is to perform a qualitative work, not to execute a set of operations on a computer. Users should be allowed to keep focus on the actual work and not bother how to manage the IT system.

Knowledge about users' cognitive abilities can be used to understand important requirements for design of functionality and interaction [9]. Examples of important design requirements are:

- Users must be allowed to have a complete and undisturbed focus on the work tasks, and handling of the technical support systems must be more or less automated.

- The support system must provide appropriate functionality (have a high utility).

- The interface must present information in a way which is consistent with human perceptive and cognitive skills and limitations, e.g. concerning limitations in short term memory.

- The interface must provide accurate feed-back, so that the user can understand it and is in full control of what happens.

- The user must always be in total control of the work process and the support system must never take over control. This is important in order to avoid a feeling of being controlled by the system.

\subsubsection{From Description of Work to IT System}

To specify the specific work tasks, activities, information content, communication, need of assistance and tools, we have used scenarios describing the work. Based on larger scenarios we created more narrowed and detailed scenarios describing the main work tasks that constitute the work in Kortedala home health care.

Based on each scenario we identified specific work tasks. There is no clear division of work into work tasks, but we tried to find a definition that provided a good structure for the work. Each work task consists of a number of activities, all with a need for information and communication. Inversely, a sequence of connected activities with the purpose to achieve a certain goal can be considered as a work task. 


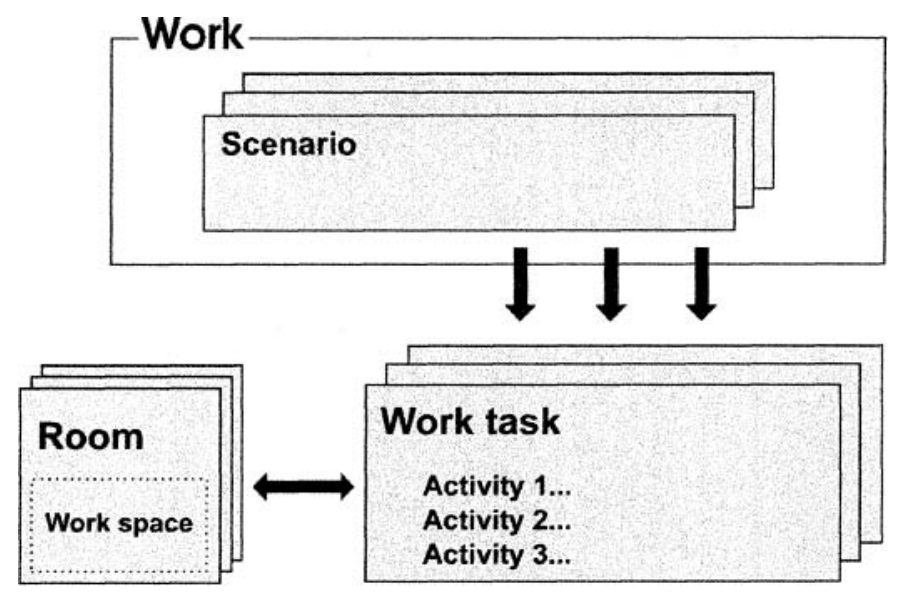

Fig. 3. Based on a number of scenarios, important work tasks can be identified. One work task consists of a number of activities and can be supported by a room or work space in the IT system's interface

\subsubsection{Design for Mobile Work}

Mobile technology can be used in order to facilitate for a stationary work to become mobile. It can also be used to support an already mobile work, as in the case of the VIHO project. The work within the home health care for elderly is, and has always been mobile, but has for long lacked IT support for the mobile work. The work place where the use of a mobile IT system occurs is often in the care takers' home or some way on the road between care takers and the office. In the VIHO project we have carefully striven for solutions that consider mobility characteristics in the work. During the work in the seminar series, three important qualities of mobile IT system have been recognized:

\subsubsection{Quick and Effective}

In the home health care, one of the mobile IT systems' most important attributes to consider is to be fast. The time available to start a device, enter or read information etc. is strongly limited. Everything that is not perceived as simple, quick and supportive will be considered as bothersome and will hardly be accepted and used by the personnel.

Examples indicates that long start-up time results in that users do not bother to read or write care documentation as intended. In the case described in [4], the startup time includes booting the device, establish the appropriate network connections, start the application - everything that is needed to set the device in such a state that the user actual can start working. This requires good hardware performance with fast networks and connections using effective verification and security procedures. Applications and interfaces are to be usable and quickly let the user carry out the actual work with a minimum of navigation in the interface. 


\subsubsection{Durable and Reliable}

In distinction to desktop work, using a stationary IT system, the circumferential environment and the contextual aspects are of much grater importance when using a mobile IT system. A mobile work imply for a constantly changing environment includes unpredictable events.

A user of a mobile device and IT system is often in need of carry out something else at the same time as using the device; driving a car or traveling with an underground railway, giving medicine, bandaging a varicose ulcer or writing a prescription. The environment can be very noisy as well as silent and include water, vomits, blood, coffee and hasty movements. Much can happen that interrupts the use. A good mobile IT system for home health care shall, as far as possible, manage the unexpected situations that can occur in the variable environments where it is used.

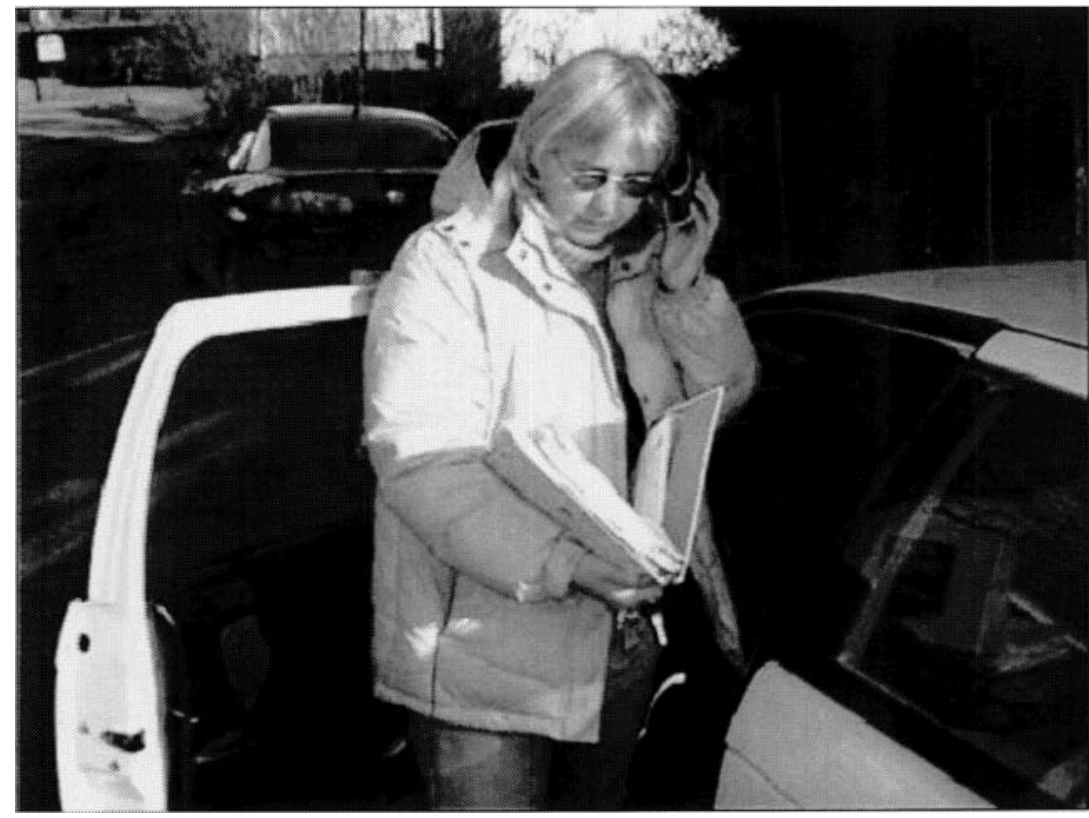

Fig. 4. Nurse in the home health care receives an urgent phone call on her way from the car to a patient

\subsubsection{Flexible}

Given the nature of mobile technology, it has to be small and easy to carry along. This affects the technology in a number of ways. When physical size is reduced, the technical performance is deteriorated. Smaller CPUs are getting slower, memory and battery time is impaired as well. As another consequence of the reduced size, the probably most important interaction channel, the screen, is reduced in size. A smaller screen implies bigger challenges to design usable graphical interfaces to the system. 
Design knowledge becomes very important and must be carefully adapted to the conditions that exist for use in mobile contexts.

\subsubsection{The VIHO Prototype}

This very first initiated phase of practical design constitutes the end of the VIHO project. We do not intend to produce a complete designed interface, but we have provided a basis for future design work.

The device of our choice does not yet exist. Technology is by all means available, but we have not found a device on the market that fully lived up to the requirements specified in the seminar work. We preferred a light weight tablet $\mathrm{PC}$ in the size of half an A4 paper. Not to big, elumsy and circumstantial to carry along but still large enough to provide a large readable screen able to display much information at the same time. Our early proposal of the interface of a supporting IT system for the mobile home care services was prototyped and look like this:

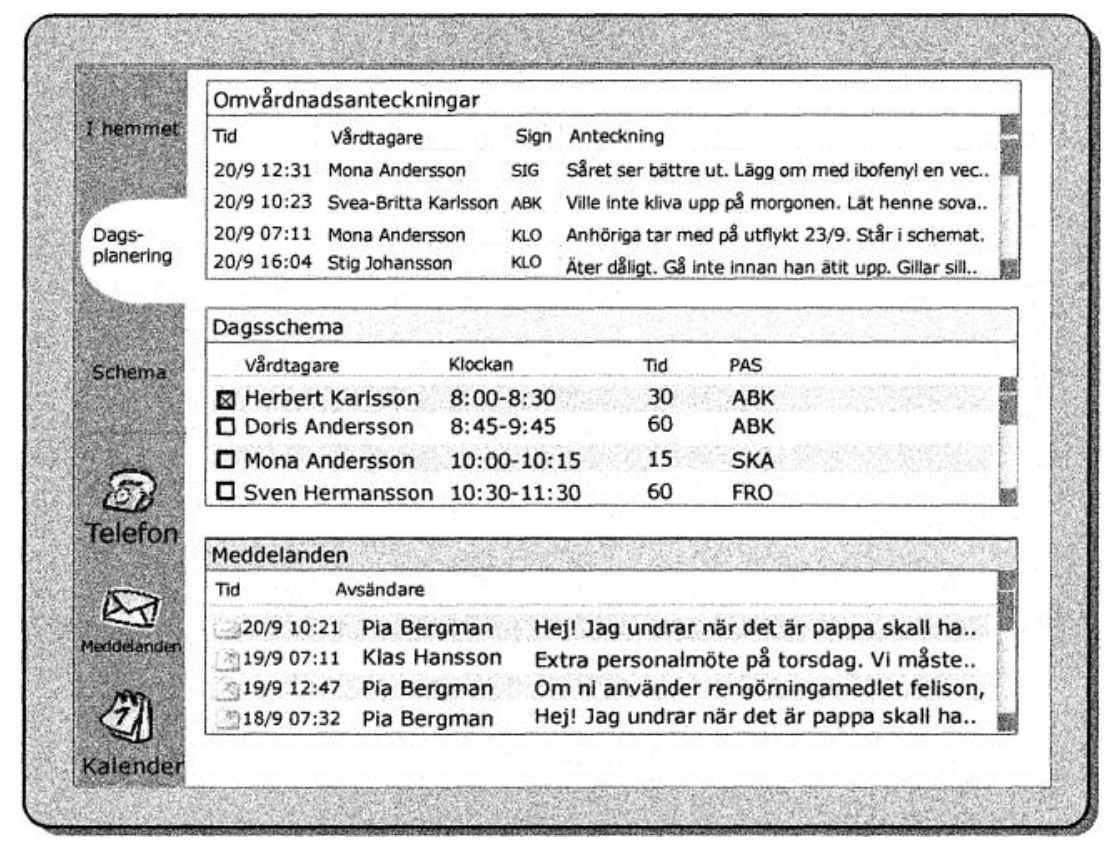

Fig. 5. Early prototype, showing overview workspace

Figure 5 illustrates when the user is using the day planning tool, showing an overview work space. This is the planning tool to use in planning situations, preferably when starting the working day. Here the user can get a quick view of the present status of the work situation. Information is displayed about today's care takers and the scheduled visits, recent documentation and messages. Choosing a specific patient in the application displays more detailed information. 


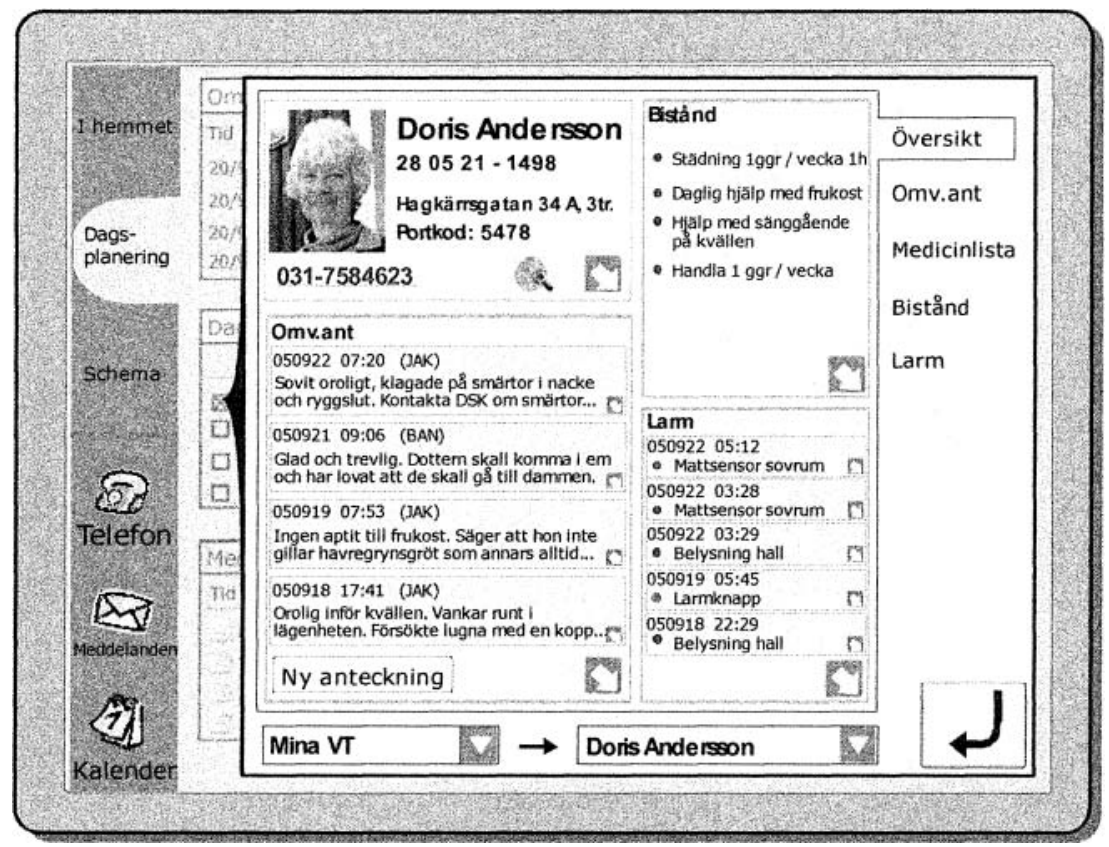

Fig. 6. Early prototype, showing detailed view

Through design of the proposed application, it is our intention to support the proposed new work by paying attention to the aspects produced in the seminars and described in the scenarios. In this case the aspects about autonomous groups, increased economic responsibility and coherent health care planning are specifically concerned. The application clearly informs about how much assistance a patient is entitled to and the nature of the assistance. This assistance is a result of one of the first decisions in the chain of care planning. If the practitioner, the user of the ITsystem, finds this amount of assistance indefensible when carrying out the assistance in practice, there are routines for sending this feedback back in the decision chain to the decision-makers. In this way the feedback forms the basis for and triggers a new care planning decision.

In this way the personnel are also given a larger economical responsibility when carrying out the work on the field. They are provided with the recent information by the IT system about their patients entitled care, but are permitted to make individually decisions effecting the present situation. Sometime a patient can need more attention at the expense of some others. This is a delicate balance and has to be handled by the personnel in the field, given supporting recourses and responsibility. 


\subsubsection{Summary}

The methodology used is intended to support a logical chain from development of work processes and work organisation, via specification of new work processes, tasks and activities to specification of requirements for supportive technical systems and design of appropriate and efficient user interfaces. Main links in the chain are:

- Analysis of present work processes and organisation. Identification of problems and development.

- Specification of important aspects that must characterise the new future work processes and organisation, i.e. the 'aspect list'.

- More detailed specification of the new work situations in terms of scenarios.

- Identification of tasks and activities of the new work situations.

- Definition of a set of 'rooms' for the technical support system, where each room corresponds to one work task for one user.

- Specification of information elements and tools needed in each specific room.

- Detailed design of the user interface in each specified room

\section{Discussion}

When introducing new IT-support systems in a work environment, it is important to keep in mind that the only relevant rationale is to contribute to improvements of the total work situation. This means that the new technical support system, to be justified, should contribute to e.g. improved quality, efficiency and a healthy and sustainable work. To improve the quality and the efficiency, it is required that not only the technology is developed, but that also the redesign of organisation, management, work processes etc must be considered. A healthy work requires that the user can handle the system with high usability and that he or she is in total control of the work process. This requires that the functionality and the dynamic interaction between the system and the user are well adapted to local needs, requirements and expectations. In order to achieve this, a user centred development process is needed. We have found that the use of workshops, or seminars, with representative groups of users, who are allowed to spend enough time to specify requirements and scenarios of future work processes, is an efficient model.

In the VIHO project, we have applied an action research approach. The seminar group consisting of researchers and practitioners has been a valuable source to knowledge about how the work presently is carried out and how visions and scenarios of the future work can be formulated. There are some problems related to this methodology, which are important to understand and consider. The seminar group must consist of experienced and engaged professionals, and they must also be given enough time to live up to the expectations. It is also important to have a very clear understanding about the mandate of the seminar group. They must be allowed to act independently at the same time they must deliver a result that is realistic. As the result is a vision of future work processes and technical support systems, it is not sure that the proposed solutions ever will be implemented, at least not to all details. This can cause false expectations and frustration. 


\section{References}

1. Olsson, E., Johansson, N., Gulliksen, J. and Sandblad, B. (2005) A participatory process supporting design of future work, Technical report, Department of Information Technology. 2005-018. ISSN 1404-3203.

2. Aborg, C. (2002): How does IT feel @work? And how to make IT better. Computer use, stress and health in office work. Doctoral thesis, Uppsala University, Sweden.

3. Karasek, R. and Theorell, T. (1990) Healthy work: Stress, productivity and the reconstruction of working life, Basic Books, New York, USA.

4. Verburg, R., Testa, S., Hyrkkanen, U. and Johansson, N. (2006) Case Descriptions of Mobile Virtual Work in Practice, In: Andriessen, E. and Vartainen, M. (Eds) Mobile Virtual Work - A New Paradigm? Springer-Verlag.

5. Masters, J. (1995) The history of Action Research. In: Hughes (ed.) Action Research Electronic Reader. The University of Sidney. Online:http://www.scu.edu.au/schools/gcm/ar/arr/arow/default.html (download date 2005-04$01)$.

6. Göransson, B. (2004) User-Centred Systems Design: Designing Usable Interactive Systems in Practice. Ph.D. dissertation. Acta Universitatis Uppsaliensis. Comprehensive Summaries of Uppsala Dissertations from the Faculty of Science and Technology 981. Uppsala, Sweden.

7. Schuler, D. and Namioka, A. (Eds) (1993) Participatory Design - Principles and Practices. Lawrence Erlbaum Associates, New Jersey.

8. Greenbaum, J. and Kyng, M. (Eds) (1992) Design at work: cooperative design of computer systems. Lawrence Erlbaum Associates, Inc.

9. Sandblad, B., Lind, M. and Nygren, E.(1991) Kognitiva arbetsmiljöproblem och gränssnittsdesign. CMD-rapport $\mathrm{nr}$ 20/91. Uppsala University, Sweden.

10. Scandurra, I., Hägglund, M., Johansson, N., Sandblad, B. and Koch, S. (2003) User needs for development of context dependent devices in mobile home care. In: Chittaro L (ed), Human-Computer Interaction with Mobile Devices and Services, LNCS 2795, SpringerVerlag, pp. 445-450.

11. Henderson, A., and Card, S. (1986) Rooms: The use of multiple virtual workspaces to reduce space contention in a window based graphical user interface. ACM Transactions on Graphics, 5(3) pp 211-243.

12. Gulliksen, J., Lif, M., Lind, M., Nygren, E., and Sandblad, B. (1997) Analysis of Information Utilisation. International Journal of Human-Computer Interaction, 9 (3).

13. Lif, M., Olsson, E., Gulliksen, J. and Sandblad, B. (2001) Workspaces enhance efficiency - theories, concepts and a case study, Information Technology \& People 14 (3) 261-272.

14. Preece, J. (1994) Human-Computer Interaction, Addison-Wesley, Wokingham, England. 